\title{
"humanidades
}

Revista Humanidades

ISSN: 2215-3934

humanidades@ucr.ac.cr

Universidad de Costa Rica

Costa Rica

\section{Da Criação Artística à Representação do Imaginário e da Cultura Popular no Gênero História em Quadrinhos}

dos Santos, Mstr. Milena; da Silva, Dr. Cícero

Da Criação Artística à Representação do Imaginário e da Cultura Popular no Gênero História em Quadrinhos

Revista Humanidades, vol. 12, núm. 1, e49213, 2022

Universidad de Costa Rica, Costa Rica

Disponible en: https://www.redalyc.org/articulo.oa?id=498068490008

DOI: https://doi.org/10.15517/h.v12i1.49213

\section{(c) (1) $(9)$}

Esta obra está bajo una Licencia Creative Commons Atribución-NoComercial-SinDerivar 3.0 Internacional. 


\section{Da Criação Artística à Representação do Imaginário e da Cultura Popular no Gênero História em Quadrinhos}

\section{From Artistic Creation to the Representation of the Imaginary, and Popular Culture in the Comic Books Genre}

Mstr. Milena dos Santos

Universidade Federal do Tocantins, Araguaina, Brasil

milenasantos11@hotmail.com

DOI: https://doi.org/10.15517/h.v12i1.49213

Redalyc: https://www.redalyc.org/articulo.oa? $\mathrm{id}=498068490008$

iD https://orcid.org/0000-0001-5652-0388

Dr. Cícero da Silva

Universidade Estadual Paulista Júlio de Mesquita Filho/

Universidade Federal do Tocantins, Araguaina, Brasil

cicolinas@yahoo.com.br

(iD https://orcid.org/0000-0001-6071-6711

Recepción: 13 Agosto 2021

Aprobación: 15 Noviembre 2021

\section{Resumo:}

Neste artigo, analisam-se elementos que caracterizam aspectos da criação artística, mímesis, representação do imaginário e da cultura popular no gênero História em Quadrinhos (HQs) produzido por acadêmicos do Curso de Licenciatura em Educação do Campo: Códigos e Linguagens - Artes e Música da Universidade Federal do Tocantins. Metodologicamente, realizou-se uma pesquisa participante, de abordagem qualitativa. Os resultados mostram que é preciso compreender a estética do gênero HQs, sua relação com a literatura, bem como a mímesis na produção artístico-literária. E um dos caminhos para entender as representações do imaginário e da cultura popular nas HQs perpassa pela criação estética e pela literatura.

Palavras-Chave: Escrita, Formação, Artes visuais, Educação do Campo.

\section{Abstract:}

This paper analyzes elements that characterize aspects of artistic creation, mimesis, and representation of the imaginary, and popular culture in the Comic books genre produced by students of the Degree in Rural Education: Codes and Languages - Arts and Music at the Federal University of Tocantins. Methodologically, a participant research was carried out, with a qualitative approach. The results show that it is necessary to understand the aesthetics of the Comic books genre, its relationship with literature, as well as mimesis in artistic-literary production. And one of the ways to understand the representations of the imaginary and popular culture in comics is through aesthetic creation, and literature.

KEYWORDS: Writing, Training, Visual Arts, Rural Education.

\section{INTRODUÇÃO}

Este artigo nasce a partir das discussões e reflexões sobre literatura na disciplina intitulada "Fundamentos em Literatura e Ensino”, ministrada no Programa de Pós-Graduação em Letras: Ensino de Língua e Literatura (PPGL) da Universidade Federal do Tocantins (UFT), Campus de Araguaína. A arte de narrar ou contar histórias é uma tradição que acompanha o ser humano desde tempos remotos. Esse tipo de tradição, outrora exclusivo da oralidade, era passado de geração em geração, ora retratando fatos reais, ora fatos da imaginação. Nessa esteira, observa-se não só a capacidade humana de comunicar às suas futuras gerações fatos históricos, mas também de manter viva a tradição de produzir "obras artísticas" para fins de entreter, discutir valores, transmitir ensinamentos, como através da fábula, por exemplo. 
No mundo da arte, sobretudo na literatura, para boa parte dos leitores realidade e ficção muitas vezes se entrecruzam e se misturam. Na literatura, a tal mímesis como estabelece Aristóteles (2000) é que vai fazer com que uma obra de ficção tenha certa aproximação com o real, isto é, o que se denomina "verossimilhança". Todavia, é preciso considerar, segundo Eagleton (1998), que elementos podem definir determinado texto como literatura ou como uma obra literária. Na verdade, para Terry Eagleton o que distancia a literatura de outros textos é o seu propósito não pragmático, em outras palavras, sua condição poética.

Dependendo do contexto em que está inserido, "cualquier texto puede leerse sin afán pragmático suponiendo que en esto consista el leer algo como literatura; asimismo, cualquier texto puede ser leído poéticamente" (Eagleton, 1998, p. 9). Nesse sentido, não existiria literatura tida como um conjunto de obras de valor segurado e inalterável caracterizado por certas propriedades intrínsecas e compartilhadas, o que não quer dizer que qualquer coisa escrita pode ser definida ou tomada como literatura. Uma produção tem seu valor poético determinado por convenções e normas sociais situadas sócio-historicamente (Eagleton, 1998). Isso significa que um texto que relata coisas que aconteceram pode ser considerado nem tanto história, mas literatura e, inversamente, um texto que relata coisas que me passaram pode ser considerado um documento histórico, além de valorizar sua qualidade literária.

Portanto, a capacidade de fazer a transposição de elementos do mundo real para uma obra artística (seja ela literária ou plástica etc.) depende sobretudo da capacidade artística do produtor/autor. Construir uma obra artística, a exemplo de uma História em Quadrinhos (HQs) é, antes de tudo, ter domínio não só da habilidade de desenhar os quadrinhos, fazer as ilustrações, por exemplo. A priori, o produtor/autor precisa ter domínio dessa estética já que precisa elaborar o roteiro da história com todos os elementos que integram esse gênero.

Nesse sentido, o objetivo deste artigo é analisar elementos que caracterizam aspectos da criação artística, mímesis e representação do imaginário e da cultura popular no gênero História em Quadrinhos produzido por acadêmicos do Curso de Licenciatura em Educação do Campo: Códigos e Linguagens - Artes e Música da Universidade Federal do Tocantins (UFT), Campus de Tocantinópolis. Trata-se de uma pesquisa participante, de abordagem qualitativa. Acreditamos que um dos caminhos para entender as representações do imaginário e da cultura popular nas HQs perpassa pela criação estética e pela literatura.

É importante destacar que estamos compreendo, segundo Bakhtin (2006), que a literatura também se enquadra como criação estética. Isso porque em uma história há dois aspectos passíveis de distinção, de um lado, o estético-formal vinvulado ao componente icônico, e, de outro, a estética narrativa relacionada ao componente verbal.

Além da Introdução, este trabalho traz outras duas partes principais. Na primeira, apresentamos a perspectiva teórico-metodológica que alicerça a pesquisa, realizamos uma ampla reflexão baseada na literatura acerca do gênero HQs, estética e sua relação com a literatura, bem como a mímesis na produção artístico-literária. Na segunda parte, desenvolvemos a discussão dos dados da pesquisa, mostrando que os colaboradores do estudo se preocuparam com a verossimilhança e a mimesis na produção de suas HQs. Por fim, listamos algumas notas sobre o estudo.

\section{HISTÓRIAS EM QUADRINHOS E RELAÇÃO COM A LITERATURA}

O gênero História em Quadrinhos (HQs) é reconhecido pela junção da linguagem verbal e não verbal, ou seja, texto e imagens, para contar uma história. É denominado como arte sequencial, que conta uma história por meio dos quadrinhos, através de imagens. "É um gênero discursivo que tem em sua estrutura fatos, personagens, tempo, possui uma linguagem clara e direta, buscando desta maneira uma clareza em sua compreensão" (Santos \& Silva, 2019, p. 103). Este gênero é comum ao homem desde a antiguidade, sendo encontrado nas tapeçarias, vitrais, mosaicos e, ainda, nas igrejas na Idade Média para a exposição de episódios como a via-sacra, ilustração da vida dos homens santos em imagens. Mas com o passar do tempo o modo de 
produção deste gênero artístico adquiriu maneiras mais práticas e rápidas de aproximação com os sujeitos mediante a cultura de massa (Araújo, Costa \& Costa, 2008).

Assim, o ato de narrar, contar história, está presente e enraizado no comportamento das sociedades desde os primórdios da humanidade. Como explica Eisner (2005, p. 11-13),

As histórias são usadas para ensinar o comportamento dentro das comunidades, discutir morais e valores, ou para satisfazer curiosidade. Elas dramatizam relações sociais e os problemas de convívio, propaga idéias ou extravasa fantasias. ... Uma história tem um início, um fim, e uma linha de eventos colocados sobre uma estrutura que os mantêm juntos. Não importa se o meio é um texto, um filme ou quadrinhos. O esqueleto é o mesmo. O estilo e a maneira de se contar pode ser influenciado pelo meio, mas a história em si não muda.

As narrativas, histórias, são criadas dentro de uma sociedade para diversas finalidades, sendo elas fictícias ou realistas, servindo para discutir questões da realidade social ou até aquelas ligadas à subjetividade de cada indivíduo. No caso dos gêneros, concordamos com Oscar Steimberg (Berone \& Reggiani, 2009) que eles podem ser classificados como ficcionais e não ficcionais. Assim, as HQs de aventura (sobre tema como: ficção científica, guerra e policial), por exemplo, são histórias realistas, enquanto que aquelas que não são realistas entram no grupo das HQs de humor. Por último, podemos citar as de gêneros não ficcionais, como documentário, autobiografia entre outras. Moya (1997, p. 23) afirma que os quadrinhos "são a forma de comunicação mais instantânea e internacional de todas as formas modernas de contato entre os homens de nosso século". Vergueiro (2009, p. 07) destaca a influência das HQs na cultura e na economia da comunicação de massa afirmando que

Os quadrinhos representam hoje, no mundo inteiro, um meio de comunicação de massa de grande penetração popular. Nos quatro cantos do planeta, as publicações do gênero circulam com uma enorme variedade de títulos e tiragens de milhares ou, às vezes, até mesmo milhões de exemplares.

Muitos pesquisadores, de diferentes áreas, ao longo dos anos vêm explorando a potencialidade que as HQs possuem em diversos segmentos metalinguísticos, políticos, sociais e econômicos. Segundo Cirne (1970, p. 17), os quadrinhos apresentam "uma problematicidade expressional de profundo significado estético, tornando se a literatura por excelência do século XX". E para haver esta problematicidade, a contação de uma história, independente do gênero, do suporte comunicativo, é necessária uma gama de elementos que irão permitir a sua expressão. Como explica Cagnin (1975, p. 155),

A narração é assim um produto de unidades articuladas segundo certos princípios. É uma série organizada de acontecimentos. Ainda que selecione fatos reais e da vida, ela não é uma mera cópia da vida. Estabelece unidades e, organizando-as, forma um conjunto de normas, o código narrativo.

Dentro das HQs podemos encontrar: narrativa, enredo, personagens, tempo, lugar e desfecho que se caracterizam como elementos que se configuram como o tecido da narrativa, pois é por meio deles que os leitores criam suas interpretações do que ver/ler/perceber na construção e interação com a obra. As HQs podem ser criadas com cunho humorístico, informativo, aventura etc. Geralmente são produções criadas para o mundo infanto-juvenil e também produções alinhadas com o cânone literário, conseguindo assim articular e circular o que muitos denominam como alta cultura e a cultura de massa.

Quanto à organização gráfica/espacial das HQs, ela é orientada por um sistema particular, mas que não se apresenta totalmente inferior às estratégias narrativas, além de não ser controlado por estas (Groensteen, 2015). Ainda segundo o autor, antes de ser delineada narrativamente, a história é concebida espacialmente pelo seu criador. Logo, a organização espacial é denominada sistema espaço-tópico (Groensteen, 2015). A concepção de história em quadrinhos perpassa pela equação entre a narrativa e a organização do espaço gráfico que se dispõe, dando forma visual à história. Groensteen (2015) ainda ressalta que o processo criativo não se limita à estruturação da narrativa, pois inclui também a distribuição de espaços e ocupação de lugares. 
$\mathrm{Na}$ obra de Groensteen (2015), a opção teórica do autor enfatiza um sistema que privilegia os aspectos formais dos quadrinhos, dando pequena ênfase em questões relacionadas a conteúdo. No entanto, as contribuições de Groensteen nos permitem tomar questões desenvolvidas nos estudos desse autor que vão muito além de uma simples análise formal das HQs.

A linguagem verbal presente nas HQs aparece “... principalmente para expressar a fala ou pensamento dos personagens, a voz do narrador e os sons envolvidos nas narrativas apresentadas, mas também estará presente em elementos gráficos, como cartazes, cartas, vitrines etc." (Vergueiro, 2014, p. 55). Ou seja, ela se manifesta a partir do diálogo, de ideia ou pensamentos que podem ser vistos no interior dos balóes, os quais de acordo com a intenção do autor na fala do personagem podem ter múltiplos formatos e classificação, além das legendas que apresentam a voz do narrador.

A linguagem não verbal possui sua parcela de importância para a construção deste gênero. A estética das HQs não é criada apenas para proporcionar beleza e alegria às páginas da história, ainda que muitas vezes sejam repletas de cores, com personagens em movimento e alegres, exprimindo gestos e emoções, com signos variados que fazem este gênero singular, também encontramos a vivacidade à leitura. Desta forma, linguagem verbal e não verbal complementam-se para tornar a HQs uma HQs, tendo o autor todas estas preocupações, com os mínimos detalhes entre as duas linguagens para que no final a história seja repleta de significado no processo de leitura.

Assim, temos um gênero discursivo (Bakhtin, 2006) que possui diversas possibilidades para seu uso na leitura, já que suas peculiaridades não se esgotam e seus signos contribuem para o entendimento da leitura e leva o leitor a refletir a partir de cada pormenor que a história possui. Ao realizar a leitura de uma HQs o leitor será "automaticamente" estimulado e incentivado a buscar novas leituras, ou seja, outros tipos de leitura, pois assim como os livros literários comuns, as $\mathrm{HQs}$ são um gênero ficcional que tem potencial para estimular a imaginação e o raciocínio dos seus leitores (Lannone \& Lannone, 1994). De certa forma, essa concepção é debatível. No ato de leitura de uma HQs, o leitor também pode ser estimulado a aprender e conhecer a linguagem das Histórias em Quadrinhos, uma vez que a compreensão deste gênero exige o aprendizado ou domínio de seus códigos de construção, os quais não parecem fáceis ou simples de compreender.

Arte narrativa por natureza, o quadrinho traz em si grande potencial comunicativo, apresentando uma união própria entre as linguagens verbal e não-verbal. Com a literatura, arte que também trabalha com a narratividade, o quadrinho tem estabelecido uma ampla interação. (Oliveira, 2008, p. 10).

É mediante a narrativa, escrita ou oral, que os indivíduos expressam suas ideias, valores, cultura. Esta narrativa pode retratar fatos verídicos ou fictícios, construída a partir de narrativas coletivas e/ou individuais. Dolz, Noverraz e Schneuwly (2004), ao realizarem a nomeação do agrupamento de gênero, deixam-nos a impressão de que o gênero HQs como manifestação humana têm características dos gêneros da categoria do narrar, pois, ao relatarem histórias, posicionam-se no domínio da cultura ficcional literária. Dessa maneira, o gênero HQs faz parte da literatura em função de sua estrutura narrativa, sendo

Conhecida também como arte sequencial, os quadrinhos constituem um gênero textual literário, uma vez que criam uma realidade ficcional; constroem narrativas dialogadas (ou não), cujo objetivo é relatar uma história em que os personagens e cenários descritos (desenhados) fazem referência a um contexto também ficcional, além de brincar com a linguagem, o que vai acontecer com mais ou menos objetividade, dependendo do público leitor - a exemplo temos os quadrinhos de Maurício de Sousa que, por serem endereçados a crianças, utilizam-se de uma linguagem mais acessível a esse tipo de público. (Barbosa, 2009 , p. 35).

Na literatura, o estético encontra-se na linguagem e através dela é possibilitado ao leitor a emoção mediante o estímulo às sensações e o deleite pelo belo ao longo de toda a leitura. No caso das HQs, a estética pode ser notada mediante variados e criativos ícones, imagens, signos que possuem diversos elementos significativos em cada pormenor. A literatura, no âmbito da arte, tem a possibilidade de expressar a vida humana na 
transfiguração do real, os acontecimentos simples e os mais aprimorados, sendo que muitas vezes o modo de construção das histórias tem a possibilidade de denunciar situações injustas e desumanas.

Assim, esse gênero tem a capacidade de possibilitar aos indivíduos refletir sobre a realidade que os rodeia, bem como acerca de diversas práticas, e ainda aprimorar a capacidade crítica e reflexiva do que é vivenciado e visto, dando assim condições para que os indivíduos consigam provocar mudanças em seu meio social, mudanças necessárias e possíveis, características de um cidadão que age ativa e autonomamente (Lajolo, 1988).

Encontramos nas $\mathrm{HQ}$ s diversas temáticas, mas ao tratar de assuntos sociais, folclóricos e culturais, o gênero também se constitui em uma forma de expressão humana e social, dando assim possibilidade para que o leitor tenha uma compreensão da realidade e de práticas que os rodeia, bem como de outras realidades e práticas, possibilitando condições de conhecer ou não novas realidades e práticas e assim refletir sobre elas. Em função de a literatura possuir uma dinamicidade cultural, ela acaba tendo um caráter de aquisição de informação, o que possibilita aos indivíduos a construção do conhecimento, ampliação e aprimoramento. Na leitura das $\mathrm{HQ}$, em sua forma artística, o indivíduo terá acesso a uma gama de assuntos diversos e educativos (Coutinho, 1978).

Lajolo (1988) explica que com o passar dos anos a literatura tem seguido a evolução social. E as HQs também vêm acompanhando essa evolução, ao criar e inserir personagens e assuntos que são encontrados na atualidade, nos fatos vivenciados pela sociedade, e pelo próprio autor que muitas vezes traz suas próprias práticas e representações de letramento, evidenciando elementos de suas comunidades (Santos, 2021). E na esfera literária, ao autor colocar em suas HQs esses recursos ficcionais ligados às circunstâncias e acontecimentos reais, traz um contato íntimo e intenso para a história e assim o leitor poderá vivenciar através da história elementos de sua trajetória de vida. De acordo com Ramos e Feba (2011, p. 214), "é, pois, da natureza da literatura a ficcionalidade, a invenção, a fabulação, a fim de representar e recriar ações humanas".

A construção de uma HQs, tanto a parte escrita quanto estética, é pessoal, pois o produtor/autor pode narrar suas experiências vividas, a forma de ver e interagir com a realidade, as escolhas pessoais, crenças, envolvimento com as questões sociais e políticas, uma vez que este autor está vinculado a uma cultura. Como afirma Cândido (2000, p. 32), “... mesmo quando pensamos ser nós mesmos, somos público, pertencemos a uma massa cujas reações obedecem a condicionamentos do momento e do meio". Ou seja, o autor tem a possibilidade de colocar nos quadrinhos a sua vivência, de modo que este recrie as coisas a partir de uma nova dimensão e isto é o que Aristóteles (2000) considera como mímesis. Ademais, retomamos aqui o ponto de vista de Eagleton (1998) ao defender, por um lado, que um texto que relata coisas que aconteceram pode ser considerado não tanto história, mas sim literatura e, por outro lado, um texto que narra coisas que se passaram comigo pode ser considerado um documento histórico. Isso porque "A arte pode também narrar coisas efetivamente acontecidas, mas só se torna arte se a essas coisas ela acrescenta um quid que falta à narração puramente histórica" (Reale, 2007, p. 178).

A principal característica de um autor é a sua capacidade mimética ou criadora, e isto se dá na imitação ou criação de ações. A poesia, a literatura, não necessita da verdade contida em sua narração, ou seja, para que um gênero se torne literário, tenha o valor de arte, não precisa necessariamente possuir a verdade que é entendida historicamente das ações, ou dos fatos criados. Vale ressaltar que “... la verdad no es necesariamente lo contrario de la ficción, y que cuando optamos por la práctica de la ficción no lo hacemos con el propósito turbio de tergiversar la verdad" (Saer, 2016, p. 15). Segundo o autor, o fictício pode carregar algo de verdade, mas na ficção os elementos da verdade são organizados e funcionam de forma diferente como eles são organizados em textos não ficcionais (o discurso acadêmico, o discurso jornalístico, por exemplo).

O autor de textos literários narrativos ao utilizar da mímesis a partir de Aristóteles (2000) construirá um texto baseado no possível e no verossímil, o qual poderá trazer fatos que imitarão as ações e os fatos e buscará torná-los universais, sendo mímesis a imitação da ação humana, e posteriormente mais ricos e criativos, considerando assim a mímesis como fonte de verdadeiro conhecimento. $\mathrm{O}$ autor explica que o objeto da 
produção artística é a imitação das ações humanas, buscando transformá-las nas obras literárias em tragédias ou comédias.

$\mathrm{Na}$ mímesis tem-se a presença de uma faceta antropomórfica, mas também existe uma preocupação acerca dos procedimentos de imitação, ou seja, os caminhos utilizados pelos autores para a criação de suas obras literárias, os modos e os meios tomados pelos autores para construir a narração, a composição geral da obra. Desta forma, a mímesis é uma atividade que o autor utiliza do imaginário sobre o real, buscando o prazer em seus leitores durante a criação, mas também produz saber. Ou seja, a obra do autor jamais será uma cópia da realidade, mas sim um trabalho ficcional pensado a partir da realidade sobre a ação humana. Sendo assim, a obra literária (objeto artístico), que está no "meio da balança”, passa a ser uma intermediária entre a ficção e a realidade.

\section{PROCEDIMENTOS METODOLÓGICOS}

Para este estudo, a geração dos dados deu-se com base nos pressupostos metodológicos da pesquisa participante (Brandão, 1998; Brandão \& Steck, 2006), pois um dos pesquisadores participou de todo o desenvolvimento de criação das HQs em sala de aula pelos colaboradores da pesquisa. Portanto, houve uma interação direta entre pesquisador e os colaboradores da pesquisa ao longo do processo de produção e geração dos dados.

A pesquisa participante tem suas origens na ação educativa, tendo grande influência dos trabalhos de Paulo Freire referentes à educação popular. O método de alfabetização de Freire está diretamente ligado ao próprio contexto sócio-histórico dos sujeitos, o que leva pesquisadores a argumentarem que daí surgem as bases da pesquisa participante. Brandão \& Steck (2006, p. 12) defendem que a pesquisa participante deve ser compreendida como um "repertório múltiplo e diferenciado de experiências de criação coletiva de conhecimentos destinados a superar a oposição sujeito/objeto no interior de processos que geram saberes e na sequência de ações que aspiram gerar transformações”.

Há diversos modelos de pesquisa participante, já que este tipo de pesquisa tem um caráter flexível e por natureza adapta-se a diferentes ambientes e situações concretas, mediante os objetos estudados, os recursos disponíveis e ainda o contexto sociopolítico em que a investigação será desenvolvida. Mas é necessário sempre ter conhecimento das bases que a regem para saber distingui-la de pesquisas que não possuem o caráter de pesquisa participante, mas sim de observação participante ou mesmo de pesquisa-ação.

Desta forma, esta pesquisa caracteriza-se como participante, de abordagem qualitativa. Para Godoy (1995), a pesquisa qualitativa não busca técnicas matemáticas para analisar dados, ou seja, não busca enumerar ou mensurar dados de pesquisa, e não utiliza ferramentas estatísticas. Mas uma de suas principais características é que pode definir "fatos", ou seja, focar no mundo real (Flick, 2009) e conectá-lo diretamente com o sujeito, mostrando a relação direta entre os dois relacionamentos. Portanto, "envolve a obtenção de dados descritivos sobre pessoas, lugares e processos interativos pelo contato direto do pesquisador com a situação estudada, procurando compreender os fenômenos segundo a perspectiva dos sujeitos, ou seja, dos participantes da situação em estudo" (Godoy, 1995, p. 58).

O conjunto de dados do estudo integra uma pesquisa mais ampla, desenvolvida para consecução de uma dissertação de mestrado (ver Santos, 2021), cujo corpus é constituído de textos de 15 exemplares do gênero HQs e trechos (transcritos) de 14 entrevistas realizadas com os colaboradores da pesquisa. Os colaboradores dessa pesquisa possuem faixa etária de 20 a 65 anos. Vale ressaltar que, neste artigo, analisamos apenas $03 \mathrm{HQ} s$ que integram o corpus do referido estudo relatado em Santos (2021). Os autores das HQs aqui analisadas possuem respectivamente 22, 26 e 30 anos de idade, sendo um indígena, um quilombola e um camponês. Todos eles vivem no campo, no interior do estado do Tocantins, região Norte do Brasil.

Os dados foram gerados na disciplina "História em Quadrinhos", ofertada no $6^{\circ}$ período do Curso de Licenciatura em Educação do Campo: Códigos e Linguagens - Artes e Música da Universidade Federal 
do Tocantins (UFT), campus de Tocantinópolis. A turma participante do estudo possui as características do público-alvo do curso, populações do campo, como agricultores familiares, ribeirinhos, assentados e acampados da reforma agrária, extrativistas, trabalhadores assalariados rurais, quilombolas, indígenas, entre outros, conforme estabelece o Decreto No 7.352 (Brasil, 2010).

\section{DISCUSSÃO E ANÁLISE DOS DADOS}

Na construção das Histórias em Quadrinhos, os colaboradores da pesquisa utilizaram da literatura mimética, ou seja, da mímesis, os temas abordados nas produções perpassam desde temas que possuem importância para a sociedade, por trazer elementos de sua cultura e identidade, até temas que levam à fuga das tensões, causando desta forma um impacto nos seus leitores. Para causar a reação desejada no leitor, os colaboradores/autores preocuparam-se com a verossimilhança e a mímesis, como veremos nos exemplos ilustrados neste artigo.

$\mathrm{Na}$ Figura 1, apresentamos um recorte da "História do Kwrytye - Kwrytye-Jayenh" do colaborador Afonso 1, um jovem indígena de 22 anos de idade. Em sua história, o autor buscou retratar um mito da cultura Apinayé, sendo o autor pertencente à etnia Apinayé. ${ }^{2}$ Trouxe uma prática significante, uma HQs repleta de bens simbólicos e da tradição cultural, ou seja, trouxe para sua história marcas da realidade indígena que ainda nos dias atuais é idealizada por muitos sujeitos se desenvolvendo mesmo que não intencional de forma estritamente atrelada ao progresso social.

Ao observar a parte gráfica da HQs (Figura 1), vê-se que o autor buscou demostrar a vestimenta dos personagens como aquelas que não são mais utilizadas nos dias de hoje. Ou seja, o autor trouxe uma "imitação" da verossimilhança, e não um fato capaz de expressar a verdade dos dias atuais. Ele trouxe, na parte gráfica, a representação da representação do que é real, não buscando retratar a verdade pura, mas procurando trabalhar em sua produção ficcional (HQs) com a semelhança dessa, ou seja, procurou adequar as vestimentas dos seus personagens de acordo com o tempo em que o mito aconteceu.

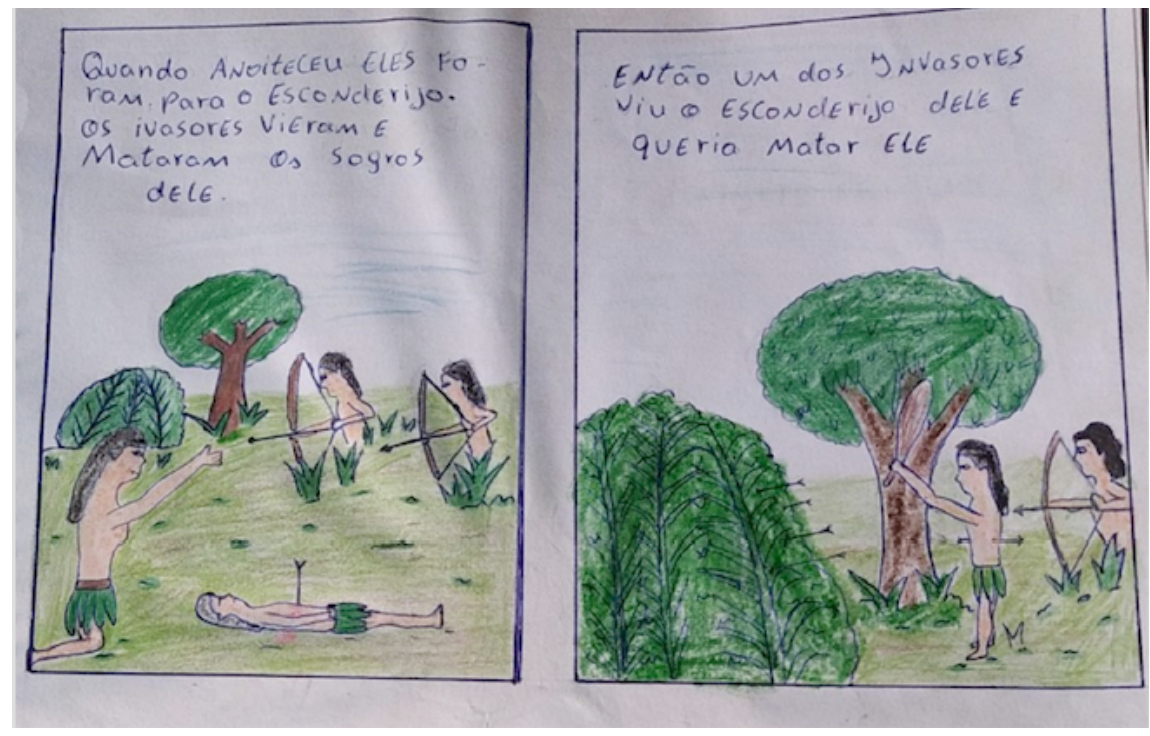

FIGURA 1.

Recorte da "História do Kwrytye - Kwrytye-Jayenh"

Fonte: HQs produzida pelo colaborador Afonso (2019).

Para a construção de sua HQs, Afonso procurou os anciões Apinayé para que estes contassem o mito do Kwrytye - Kwrytye-Jayenh. Tal mito foi contado por meio da oralidade, não possuindo nenhuma grafia/ desenho e, apesar disso, o autor trouxe sua perspectiva, seu imaginário daquele fato, daquele mito. A forma como foi apresentada por Afonso, a linguagem visual do que estava sendo contado pelos ancióes e a mímesis 
do seu mundo imaginário dá condições para que os leitores compreendam todo o contexto narrado na história, mesmo sendo a HQs uma obra de ficção. Em sua história, o autor trouxe o que Umberto Eco (2008) denomina de paradoxo narrativo, isto é, o modo como uma narrativa, uma história, procura introduzir-se em dois esquemas temporais diferentes: o tempo do mito e o tempo cotidiano.

$\mathrm{Na}$ cena ilustrada na Figura 1, a linguagem visual contribui para que a imagem exceda a barreira da visualidade simples e ganhe contornos de uma verossimilhança, reformulando o modo de vestimentas e vivência de outrora dos Apinayé. Note-se que o todo da composição visual é que torna possível que a história seja entendida como ocorrida em outro tempo. Certamente, para que a visualização verossímil surtisse efeito, o autor trouxe outros elementos, símbolos elementares como as flechas. Desta forma, o autor praticou a mímesis em sua história ao conseguir retirar seus personagens, sua história, do plano da realidade e os investir de características, de possibilidade e verossimilhança, assim conseguindo ser verossímil por ter conseguido fazer parte de um todo, de maneira coerente e coesa (Reale, 2007).

Um elemento que chama bastante atenção nesta história é a não utilização dos balóes, que são bastante característicos das Histórias em Quadrinhos. As falas escritas à mão, a visualização da letra do autor, possibilitam o entendimento de que haja uma maior aproximação psicológica, pessoal, do autor com a sua história. Visualmente, os balóes são aquelas 'nuvenzinhas' que encontramos ao longo das HQs que contêm um texto, uma fala de um personagem da narrativa, ou aquela caixa de texto, o recordatório, que é atribuída ao narrador externo à narrativa. Afonso utilizou apenas do recordatório sem moldura ao longo de toda a sua história, mostrando apenas falas do narrador. As HQs são bastante flexíveis, mesmo tendo esses elementos que são característicos deste gênero, a presença ou não, destes elementos não irá definir se a narrativa é uma HQs ou não. Hoje, encontramos HQs que não apresentam quadrinhos em suas narrativas, mas mesmo assim ainda são consideradas como tais (Presser, Braviano \& Fialho, 2017). Adriano, em sua história, também não trouxe dois elementos que são característicos das HQs: balóes e quadros.

Já a Figura 2 apresenta um recorte da "História do Capim Dourado no Jalapão", que é de autoria de Adriano, um jovem quilombola de 26 anos de idade. Essa HQs traz duas cenas sem requadro, separadas apenas por uma linha, mas o leitor pode compreender que são duas seções marcadas pela movimentação do personagem. É válido ressaltar que não é via de regra que as cenas sejam separadas por requadro, ou em formato de quadrinho, alguns autores fazem o requadro em forma triangular, circular, ondular, entre outras formas. A forma como foi colocada a personagem em cada uma das cenas dá a ilusão de passagem do tempo, compondo assim a narrativa. 


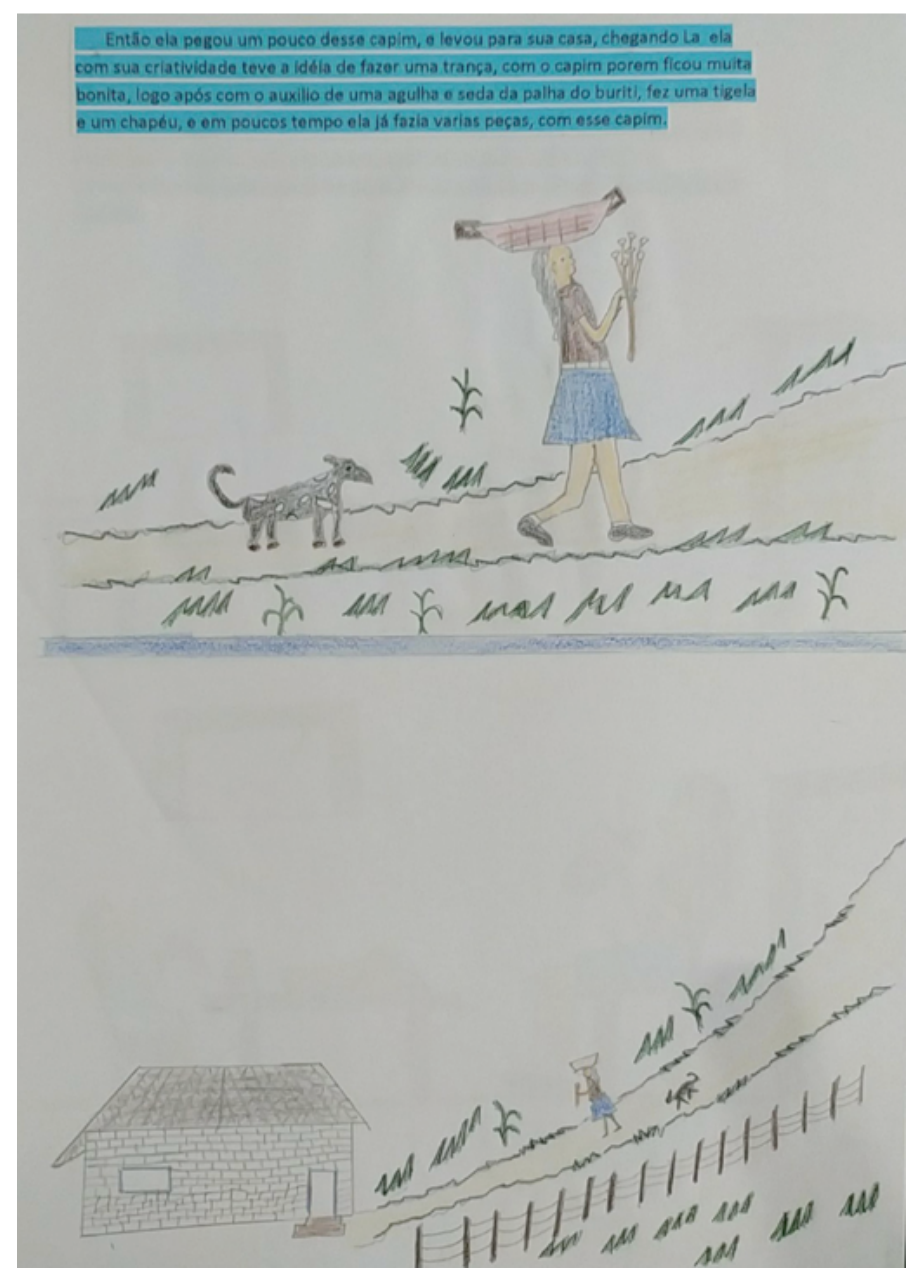

FIGURA 2.

Recorte da HQs: História do Capim Dourado no Jalapão Fonte: HQs produzida pelo colaborador Adriano (2019).

Adriano mostra com a construção da HQs sem requadro a importância do papel do leitor, cabendo a este a elaboração de sentido na história, devendo o leitor também reconhecer os signos das artes visuais e da literatura, para assim compreender que são dois requadros. Eisner (1989, p. 08) reforça esta ideia argumentando que

... a configuração geral da revista em quadrinhos apresenta uma sobreposição de palavra e imagem, e, assim, é preciso que o leitor exerça as suas habilidades interpretativas visuais e verbais. As regências da arte (por exemplo, perspectiva, simetria, pincelada) e as regências da literatura (por exemplo, gramática, enredo, sintaxe) superpõem-se mutualmente. A leitura da revista de quadrinhos é um ato de percepção estética e de esforço mental.

Nesse sentido, o autor da HQs (Figura 2) foi bastante ousado, trazendo elementos, signos sem ter a certeza de que os seus leitores iriam compartilhar dos mesmos para entendimento da HQs. Depreendemos que o autor construiu sua história apostando que os leitores conheciam os repertórios sígnicos do gênero. E é visível que este processo deu certo, pois com a análise vê-se que o objetivo, a comunicação da história foram plenamente alcançados, uma vez que conseguiu fazer com que o leitor compreendesse a função primordial do requadro, mesmo sem requadro, que é demarcar os signos constituintes da gramática dos quadrinhos, demarcar visualmente a área da narrativa, situar o ritmo da história, constituir as divisões de tempo e espaço, mas essas são apenas algumas das infinidades de significados e funções que o requadro possui na composição de uma HQs. 
A fala foi apresentada de forma contínua e sem balão, sendo a história constituída apenas pela fala do narrador. Adriano também utilizou apenas do recordatório sem moldura na construção de sua história. Nesta HQs, o autor narra a história do descobrimento do capim dourado como matéria-prima para construção de peças artesanais pelos moradores do quilombo Mumbuca, situado no Parque do Jalapão, estado do Tocantins. Ele trouxe para sua HQs o imaginário visual da história que foi a ele contada de forma oral pelos seus antepassados. Assim como na HQs de Afonso (Figura 1), Adriano trouxe a mimesis. A HQs juntamente com a mimesis possibilitou a Adriano uma autonomia, que lhe propiciou uma experimentação impraticável quanto à criação de uma parte gráfica da história que foi a ele contada apenas oralmente, tornando assim a HQs um gênero multidisciplinar por englobar elementos da HQs, literatura, história de vida e psicologia, concretizando-se em uma forma desafiadora de registrar e narrar histórias.

Adriano trouxe um acontecimento humano, uma história verídica de sua cultura, e realizou a interpretação através da arte ficcional, por meio dos quadrinhos, transversalmente por um gênero que se encontra na fronteira entre arte e a cultura de massa, identificando-a como mímesis ou "interpretação da realidade através da representação literária” (Auerbach, 2011, p. 499). Diferentemente de Adriano, que baseou sua história ficcional em fatos verídicos de sua comunidade (Figura 2), Alberto, que é um camponês de 30 anos de idade, trouxe um causo (Figura 3), o qual, como argumenta Oliveira (2006), é um gênero encontrado no cotidiano, possui uma narrativa curta, é um gênero que faz parte da cultura oral, mas pode ser encontrado na forma escrita, e faz parte da cultura popular, sendo passado de geração a geração. Como é um gênero muito antigo, o causo pode ser contado por quem viveu o ocorrido ou por quem já ouviu a história. São característicos desse gênero o exagero, a dramatização, a expectativa e o suspense. Também existe no causo a preocupação em agradar quem está ouvindo a história, buscando ter uma relação interativa e, por isto, os causos possuem um enredo repleto de fatos singulares, criativos, reais, fictícios etc.

Alberto reproduziu o causo de um jovem que consome bastante bebida alcoólica e, em seguida, pega sua motocicleta e sai a pilotar. No meio do caminho, o jovem depara-se com uma onça pintada, a qual o ataca, subtraindo sua mala que estava na parte traseira da motocicleta. No final da história, o jovem para seu veículo, ajoelha-se no meio da estrada e agradece por não ter morrido em decorrência do ataque do animal selvagem, mas não percebe que sua mala havia sumido. Ao contrário dos outros dois autores supracitados, Alberto traz os elementos que compõem o gênero HQs: narrativa dentro do requadro e balão.
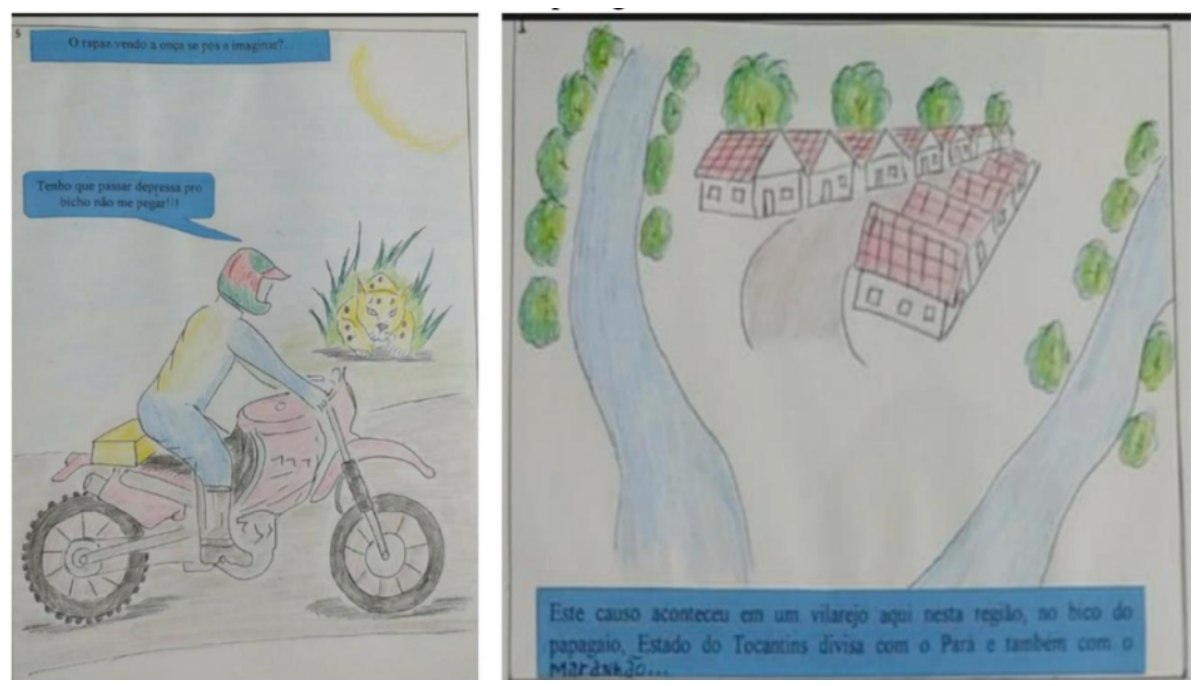

FIGURA 3.

Recorte da HQs: Branco Pereira de Sá e a Onça que cobrava pedágio Fonte: HQs produzida pelo colaborador Alberto (2019).

O causo pertence ao domínio social da cultura literária ficcional, tendo em sua formação uma predominância da habilidade de linguagem da "mímese de ação através da criação da intriga no domínio do 
verossímil” (Dolz, Noverraz \& Schneuwly, 2004, p. 60). O causo apresentado por Alberto está situado nas representações imaginárias e fantásticas, uma vez que a temática desse tipo de gênero descreve acontecimentos e costumes particulares de quem, da comunidade e do universo do indivíduo que o contou. Na composição da HQs, Alberto mesclou fatos reais com o imaginário.

\section{CONCLUSÃO}

O gênero HQs foi desenvolvendo sua linguagem própria ao longo dos anos, com seu aspecto técnicoartístico e a criação de elementos, histórias que inseriram a mimesis e a verossimilhança no enredo. Possui uma capacidade de exercitar a criatividade de quem a escreve. A HQs é reconhecida muitas vezes por seus elementos constitutivos, mas nem sempre é simples e de fácil entendimento, embora este gênero tenha como característica a utilização de imagens, onomatopeias que propiciem a aceitação mais rápida dos leitores. Sua análise é permeada de complexidade e aceitabilidade, que deve ser compreendida e analisada desde o sentido posto nas imagens, nas cores, na escrita até o paralelo com o mundo que a cerca. Evidentemente, isto ficou bastante explícito durante a análise dos dados. As HQs aqui analisadas conseguiram fazer da mímesis o fundamento de suas histórias, não visaram reproduzir ou copiar passivamente o contexto, a aparência dos objetos e pessoas, a cultura original, mas sim recriar o mito, o causo segundo uma nova dimensão, com uma nova lógica que fosse possível de entendimento aos leitores. Portanto, os resultados corroboram que é preciso compreender a estética do gênero HQs, sua relação com a literatura, bem como a mímesis na produção artístico-literária. E um dos caminhos para entender as representações do imaginário e da cultura popular nas HQs perpassa pela criação estética e pela literatura.

\section{Agradecimentos}

Registramos nossos agradecimentos à Coordenação de Aperfeiçoamento de Pessoal de Nível Superior (CAPES) pela concessão de bolsa de estudo à primeira autora para realização desta pesquisa.

\section{REFERÊNCIAS}

Araújo, G. C., Costa, M. A. \& Costa, E. B. (2008). As histórias em quadrinhos na educação: possibilidades de um recurso didático-pedagógico. A MARgem - Estudos, 1(2), 26-36.

Aristóteles. (2000). Poética. Tradução de Baby Abrão. Nova Cultural.

Auerbach, E. (2011). Mimesis. Perspectiva.

Bakhtin, M. (2006). Estética da criação verbal. Martins Fontes.

Barbosa, R. E. (2009). Da memória social à memória discursiva: marcas identitárias na revista A Turma da Mônica [Tese de Doutorado, Universidade Federal da Paraíba, João Pessoa].

Berone, Lucas \& Reggiani, F. (2009). Entrevista a Oscar Steimberg: "Lo que tiene de bueno la historieta es que es imposible”. En Leyendo Historietas, Textos sobre relatos visuales y humor gráfico. Buenos Aires.

Brandão, C. R. (1998). Participar-pesquisar. En C. R. Brandão (Org.), Repensando a pesquisa participante (pp. 07-14). Brasiliense.

Brandão, C. R. \& Steck, D. R. (2006). Pesquisa participante: o saber da partilha. Ideias \& Letras.

Brasil. (2010). Decreto No 7.352, de 4 de novembro de 2010. Dispóe sobre a politica de educação do campo e o Programa Nacional de Educação na Reforma Agrária - PRONERA. Brasília. http://www.planalto.gov.br/ccivil_03/_ato 2007-2010/2010/decreto/d7352.htm

Cagnin, A. L. (1975). Os quadrinhos. Ática.

Cândido, A. (2000). Literatura e Sociedade. T. A. Queiroz. 
Cirne, M. (1970). A explosão criativa dos quadrinhos. Editora Vozes.

Coutinho, A. (1978). Notas de teoria literária. Civilização Brasileira.

Dolz, J., Noverraz, M. \& Schneuwly, B. (2004). Sequências Didáticas para o oral e a escrita: apresentação de um procedimento. En J. Dolz \& B. Schneuwly (Orgs.), Gêneros orais e escritos na escola (pp. 95-128). Trad. e Org. de Roxane Rojo e Glaís Sales Cordeiro. Mercado das Letras.

Eagleton, T. (1998). Introducción: ¿Qué es la literatura? En T. Eagleton, Una introducción a la teoría literaria (pp. 5-14). FCE.

Eco, U. (2008). Apocalipticos e integrados. Perspectiva.

Eisner, W. (2005). Narrativas gráficas. Tradução de Leandro Luigi Del Manto. Devir.

Eisner, W. (1989). Quadrinhos e arte sequencial. Martins Fontes.

Flick, U. (2009). Introdução à pesquisa qualitativa. Artmed.

Godoy, A. S. (1995). Introdução à pesquisa qualitativa e suas possibilidades. Revista de Administração de Empresas, $35(2), 57-63$.

Groensteen, T. (2015). O sistema dos quadrinhos. Marsupial.

Lajolo, M. (1988). O que é literatura. Brasiliense.

Lannone, L. R. \& Lannone, R. A. (1994). O mundo das histórias em quadrinhos. Moderna.

Moya, Á. (1997). SHAZAM! Perspectiva.

Oliveira, M. C. X. (2008). A Arte dos "Quadrinhos" e o Literário: a contribuição do diálogo entre verbal e o visual para a reprodução e inovação dos modelos clássicos de cultura [Tese de Doutorado, Universidade de São Paulo].

Oliveira, I. R. (2006). Gênero Causo: narrativa e tipologia [Tese de Doutorado, Universidade Católica de São Paulo].

Presser, A., Braviano, G. \& Fialho, F. (2017). O uso criativo dos elementos na nova fase das Histórias em Quadrinhos no Brasil. Revista Triades, 6(1), 01-17.

Ramos, F. B. \& Feba, B. L. T. (2011). Leitura de história em quadrinhos na sala de aula. En R. J. Souza \& B. L. T. Feba (Org.), Leitura literária na escola (pp. 26-41). Mercado de Letras.

Reale, G. (2007). Aristóteles: História da filosofia grega e romana vol. IV. Tradução de Henrique Cláudio de Lima Vaz e Marcelo Perine. Edições Loyola.

Saer, J. J. (2016). El concepto de ficción. Rayo Verde Editorial.

Santos, M. \& Silva, C. (2019). O gênero história em quadrinhos no ensino: uma análise de livro didático de língua portuguesa. Web-Revista SOCIODIALETO, 10(29), 101-121.

Santos, M. (2021). O gênero história em quadrinhos como recurso metodológico para análise das práticas e representaçôes de letramento de educandos da Educação do Campo [Dissertação de Mestrado, Universidade Federal do Tocantins, Araguaína].

Vergueiro, W. (2009). Uso das HQs no ensino. En A.Rama, W. Vergueiro, A. Barbosa, P. Ramos \& T. Vilela. (Org.), Como usar histórias em quadrinhos na sala de aula (pp. 07-29). Contexto.

Vergueiro, W. (2014). A linguagem dos quadrinhos: uma "alfabetização" necessária. En A. Rama, W. Vergueiro, A. Barbosa, P. Ramos \& T. Vilela (Orgs.), Como usar histórias em quadrinhos na sala de aula (pp. 31-64). Contexto.

\section{Notas}

1 Por questôes éticas, os nomes dos colaboradores da pesquisa foram substituídos por pseudônimos que nos permitem distingui-los.

2 Os Apinayé são um dos sete povos indígenas do estado do Tocantins, sendo que as terras dessa etnia estão localizadas na microrregião do Bico do Papagaio. 